\title{
CARACTERIZAÇÃO DA PRODUÇÃO AGRÍCOLA E DOS FEIRANTES DA AGRICULTURA FAMILIAR NO MUNICÍPIO DE SÃO LOURENÇO DO SUL-RS
}

\author{
Darwin Aranda CHUQUILLANQUE ${ }^{1}$ \\ Carmem Rejane Pacheco PORTO² \\ Marcelo Tempel STUMPF ${ }^{3}$ \\ Gracieli TRENTIN 4 \\ Ana Silvia ROLON 5
}

\section{Resumo}

Esta pesquisa buscou caracterizar a situação produtiva e socioeconômica de 14 feirantes da praça central do município de São Lourenço do Sul/RS, através da aplicação de questionários. A pesquisa foi desenvolvida de fevereiro a março de 2015. Não foram identificadas pessoas com idade inferior a 35 anos entre os entrevistados, podendo indicar que os jovens se dedicam à outras atividades não relacionadas à produção e comercialização de produtos agrícolas. Em relação à escolaridade, as respostas relativas à ausência desta ou frequência até o Ensino Médio somam $72 \%$. Constatou-se que o trabalho da mulher é bem valorizado: 13 do total de entrevistados consideram fundamental para o sucesso da produção e comercialização. A renda média dos feirantes é $\mathrm{R} \$ 1.363,85$ mensais. A feira é o principal canal de comercialização dos produtores da agricultura familiar. De acordo com os feirantes, a vantagem de comercializar os produtos na feira é a eliminação do atravessador. A maioria da produção (54\%) é convencional, o que representa um campo a ser explorado para conversão a sistemas mais sustentáveis. No âmbito socioeconômico há vínculo entre produtores e consumidores e a renda obtida através da feira foi considerada satisfatória.

Palavras-chave: Agricultura familiar. Feira. Comercialização direta.

\footnotetext{
1 Acadêmico do curso de graduação em Agroecologia, Universidade Federal do Rio Grande- FURG, Campus São Lourenço do Sul. E-mail: darwinaranda@furg.br

2 Universidade Federal do Rio Grande- FURG, Campus São Lourenço do Sul. E-mail: carmem.porto@furg.br

3 Universidade Federal do Rio Grande - FURG, Campus São Lourenço do Sul. E-mail: marcelo.stumpf@furg.br

4 Universidade Federal do Rio Grande- FURG, Campus São Lourenço do Sul. E-mail: gracieli.trentin@furg.br

${ }^{5}$ Universidade Federal do Rio Grande- FURG, Campus São Lourenço do Sul. E-mail: asrolon@furg.br
} 


\section{Abstract}

\section{Characterization of agricultural production and of family farming traders in São Lourenço do Sul-RS}

This research aimed to characterize the productive and socioeconomic situation of 14 stallholders from the central square of the municipality of São Lourenço do Sul / RS, through the use of questionnaires. The research was conducted from February to March 2015. There were no people under the age of 35 years among respondents, which may indicate that young people engage in other activities not related to the production and commercialization of agricultural products. About education, the answers for the absence of formal education or attendance until the end of high school totalize $72 \%$ of respondents. It was found that women's work is well appreciated: 13 of respondents consider it crucial for the success of production and commercialization. The average income of the stallholders is $\mathrm{R} \$ 1.363,85$ a month. The market is the main commercialization channel for family farmers. According to the market vendors, the advantage of commercializing the products at the market is the elimination of the middleman. Most of the production ( $54 \%$ ) is conventional, which represents a field to be exploited for the conversion to more sustainable production systems. In the socioeconomic context, there is a link between producers and consumers and the income obtained from the market was considered satisfactory.

Key words: Family farming. Market. Direct marketing.

\section{INTRODUÇÃO}

A agricultura familiar ocupa $75 \%$ da mão de obra no campo e é responsável por $70 \%$ do abastecimento de alimentos que são consumidos pela população brasileira (Ministério do Desenvolvimento Agrário, 2012). Fica evidente que a agricultura familiar gera trabalho e renda contribuindo para o desenvolvimento local.

Conforme sustenta Panzutti e Monteiro (2015) os agricultores familiares sempre foram marginalizados pelo poder público e é a partir da reforma da Assembleia Nacional Constituinte em 1987 que a agricultura familiar é inserida na pauta governamental, a em 1996, com o lançamento da linha de custeio diferenciado para agricultura familiar do Programa Nacional de Fortalecimento da Agricultura Familiar - PRONAF (BACCARIN et al. 2016).

Mesmo que a agricultura familiar tenha ganho um relativo espaço nas agendas do governo nas últimas décadas, o que resultou em políticas públicas, ainda é presente entre os agricultores a necessidade de fortalecimento do setor, tanto na produção como na comercialização. A comercialização é considerada um gargalo para o escoamento da produção, portanto, faz-se necessário a criação e fortalecimento de espaços que visem a comercialização dos produtos da agricultura familiar.

Entre as estratégias de comercialização destaca-se o Circuito Curto Agroalimentar (CCA), conceituado pela Rede Rural Nacional de Portugal "como um modo de comercialização de venda direta do produtor para o consumidor ou por venda indireta, com a condição de não haver mais de um intermediário" (2013)Entre esses há uma proximidade geográfica e relacional.

O CCA modifica as relações entre a produção, comercialização e consumo alimentar, trazendo um conjunto de benefícios de caráter social, cultural e econômico. Nesta perspectiva, Santos (2005) considera esse modelo de serviço como o "circuito inferior da economia urbana", sendo o "circuito superior" composto por grandes ata- 
cadistas, indústrias e multinacionais. Para resistir frente às desvantagens de poder aquisitivo entre os "circuitos", Singer (2002) propõe o "consumo solidário", que nada mais é do que dar preferência aos produtos produzidos por associações ou empreendimentos solidários. O mesmo autor propõe que os consumidores devem ser incentivados a evitar o consumo de produtos pela aparência ou preço e, sim, ter em conta a qualidade e procedência do mesmo, dando preferência a produtos locais e de estação.

Conforme sustenta Steiner (2006), na "Sociologia Econômica", os mercados são formas sociais de concentração em que as pessoas criam laços coletivos. Tomando como referência a definição anterior, podemos dizer que as feiras são modelos de mercado que não só buscam a maximização do lucro, mas também se preocupam com o contexto e as relações sociais entre os indivíduos. Nesse modelo de venda direta preconiza-se o fortalecimento da economia local (MEDEIROS ; MARQUES, 2013, p.114).

As feiras livres representam espaços tradicionais onde os trabalhadores da agricultura familiar comercializam seus produtos (varejo) diretamente de suas lavouras (produtos in-natura) ou quando processados são usados procedimentos básicos ou processados por meio de procedimentos simplificados, que permitem aos agricultores familiares atuarem em outras etapas importantes da cadeia produtiva, que são os setores secundário e terciário.

As feiras livres são acontecimentos frequentes que ocorrem em espaços públicos (praças e ruas) e caracterizam-se por ser um canal de comercialização dos produtos da agricultura familiar, os quais raramente recebem apoio de políticas públicas específicas. Quando presentes, os programas tendem a ser voltados para a produção, deixando para segundo plano o caráter social, ao qual Pierri (2010) faz referência. De acordo com Steiner (2006), redes são atores ligados direta ou indiretamente, que podem apresentar interações sociais, sendo que essas podem ser transações realizadas entre pessoas de um mesmo bairro. A partir da ideia de uma rede consideramos que as feiras podem ser uma forma de organização formal ou informal que buscam interação entre atores (produtores, consumidores e público em geral), podendo ser também uma estratégia de desenvolvimento local e regional.

No território brasileiro, assim como no estado do Rio Grande do Sul, a agricultura familiar tem uma grande relevância na economia e cultura do povo gaúcho, sendo recorrente o acontecimento de feiras livres. Em São Lourenço do Sul (Figura 1), entre os pontos de comercialização destaca-se uma pequena feira junto à Praça Central Dedê Serpa, que proporciona a comercialização dos alimentos produzidos pelas próprias famílias feirantes provenientes dos distritos do município. A feira na Praça Dedê Serpa não tem um registro exato sobre a data de sua criação, tendo aproximadamente 40 anos. Segundo os relatos, as atividades da feira iniciaram-se com três feirantes e atualmente a feira congrega aproximadamente 16 feirantes na praça da cidade (Distrito Sede), sendo que essa quantidade de feirantes pode variar de acordo a estação do ano, sendo que no inverno a tendência é diminuir e no verão a mesma tende a aumentar.

As feiras são reconhecidas como espaços de abastecimento de alimentos frescos, que possuem identidade e onde é possível conhecer o agricultor e ter conhecimento sobre a origem do alimento. Ademais, são espaços de solidariedade, de socialização de conhecimento e com forte componente cultural. É uma forma de resistência dos pequenos agricultores frente ao avanço do "agronegócio" e a comercialização em larga escala. A presente pesquisa foi realizada com o objetivo de caracterizar a produção agrícola familiar e aspectos socioeconômicos e de satisfação dos feirantes do município de São Lourenço do Sul-RS. 


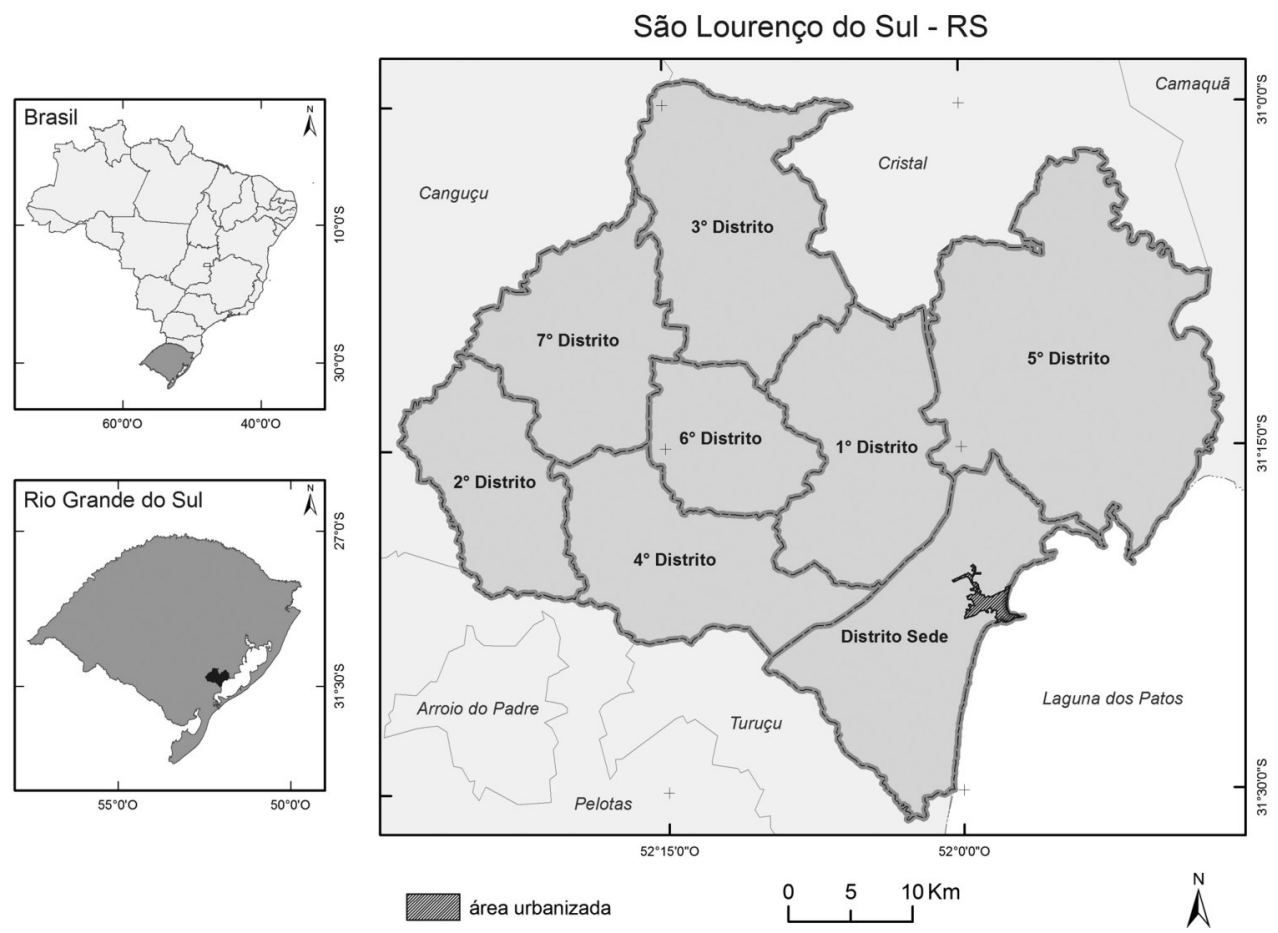

\section{Figura 1 - Localização geográfica do município de São Lourenço do Sul no estado do Rio Grande do Sul, sua divisão distrital com destaque para a área urbanizada}

Fonte: IBGE (2007), Prefeitura Municipal de São Lourenço do Sul (1990).

\section{CARACTERÍSTICAS DO MUNICÍPIO E PROPOSIÇÃo METODOLÓGICA}

A pesquisa foi realizada entre fevereiro e março de 2015 na feira localizada na praça central do município de São Lourenço do Sul-RS, o qual conta com sete distritos, além do Distrito Sede (Figura 2) e, de acordo com o IBGE (2010), possui população de 43.111 habitantes, distribuídos entre o campo (18.874 habitantes) e a cidade (24.237 habitantes). A escolha do município se deu porque nele a agricultura familiar é predominante e a transformação que ocorreu na agricultura brasileira, por meio da organização dos agricultores, do modelo de produção, distribuição e consumo dos produtos oriundos da agricultura familiar se faz presente. Além das características mencionadas a escolha também se deve à inserção da Universidade Federal do Rio Grande (FURG) e do curso de Agroecologia no município, que visa o fortalecimento da agricultura familiar por meio de práticas sustentáveis. A feira foi selecionada por ser o principal ponto de venda direta da agricultura familiar no município, mas, por se localizar na praça central, também se configura como um ponto de encontro e sociabilidade. 

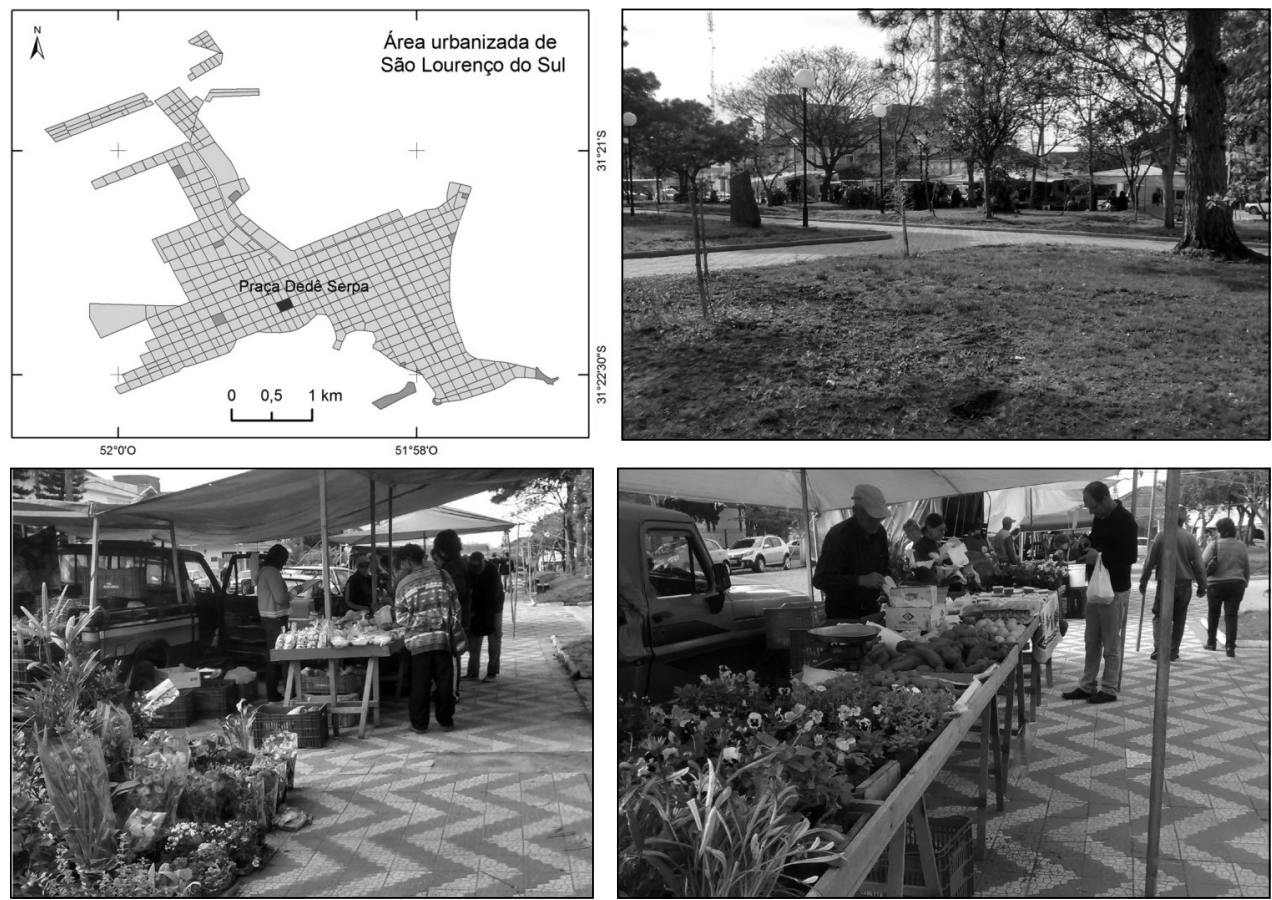

Figura 2 - Feira da Agricultura familiar no perímetro da Praça Dedê Serpa na área urbana do município São Lourenço do Sul, RS

Fonte: Imagem da pesquisa, (2016).

Os procedimentos metodológicos adotados foram: levantamento de informações básicas sobre a comercialização dos produtos na feira, através de contatos com os próprios feirantes e com a Prefeitura Municipal; elaboração e aplicação de Quatorze (14) questionários a totalidade dos feirantes submetidos à pesquisa. Todos os feirantes assinaram termo de ciência e consentimento para uso dos dados fornecidos.

Para o acesso às informações sobre os feirantes e sua produção foi elaborado um questionário contendo questões objetivas e subjetivas, divididas em três blocos: 1) Identificação: idade; renda obtida exclusivamente na feira; 2) Caracterização da propriedade e da comercialização: localização (distrito); principais produtos comercializados; vantagens e desvantagens de comercializar na feira; caracterização da produção (orgânica ou convencional); 3) Nível de satisfação: satisfação com a forma de comercialização; satisfação com a renda obtida na feira. Para conhecer a distribuição de frequências e o número de classes das idades dos feirantes utilizamos a regra de Sturges.

\section{APRESENTAÇÃO E ANÁLISE DOS RESULTADOS}

O maior número de feirantes é proveniente do Distrito 1 (Figura 3). A disparidade no número de feirantes entre o distrito 1 (6 feirantes) e os demais serve de indicativo para a tomada de decisões por parte do poder público no intuito de integrar produto- 
res e fortalecer a participação de agricultores familiares de distritos com menor representatividade na cadeia de comercialização. Além disso, a metodologia utilizada nessa pesquisa pode servir de modelo para outros municípios, para que os mesmos obtenham um cenário da distribuição espacial dos feirantes e possam tomar decisões pontuais nas regiões menos representativas.

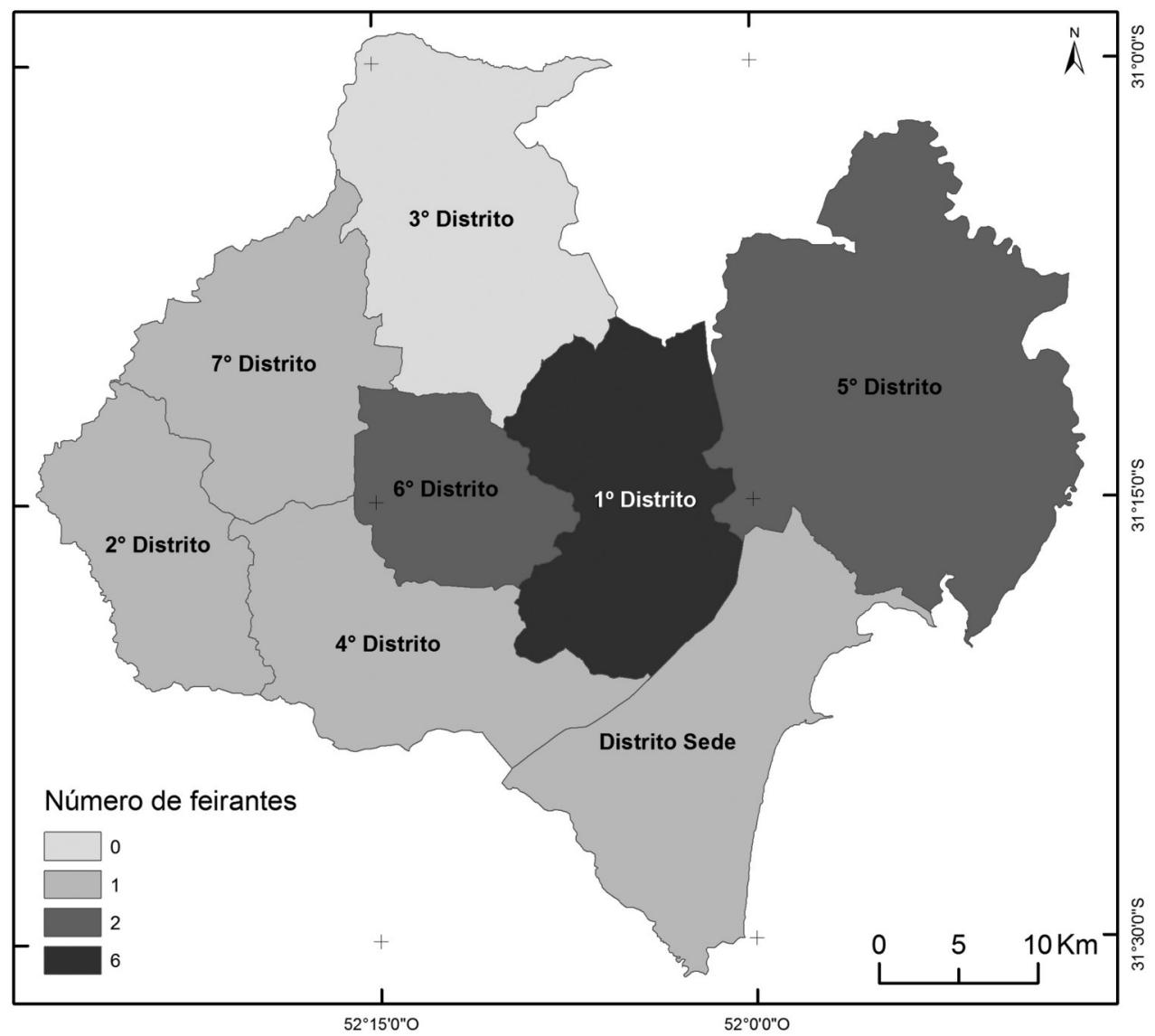

\section{Figura 3 - Distribuição por distrito das propriedades das famílias que trabalham na feira da Praça Dedê Serpa do município de São Lourenço do Sul, RS}

Fonte: Dados da pesquisa, (2015).

Os produtos mais vendidos na feira são: batata, cebola, feijão, batata doce, bolachas e abóbora (Figura 4). Como a pesquisa foi realizada em meses de verão, percebe-se que tanto as verduras como as frutas não apresentaram uma relevante disponibilidade em termos de oferta nesse período; no caso das verduras pode ser porque alguns produtores não possuem sistemas de irrigação ou, se contam com esse sistema, a disponibilidade hídrica é insuficiente para realizar irrigação na lavoura. 


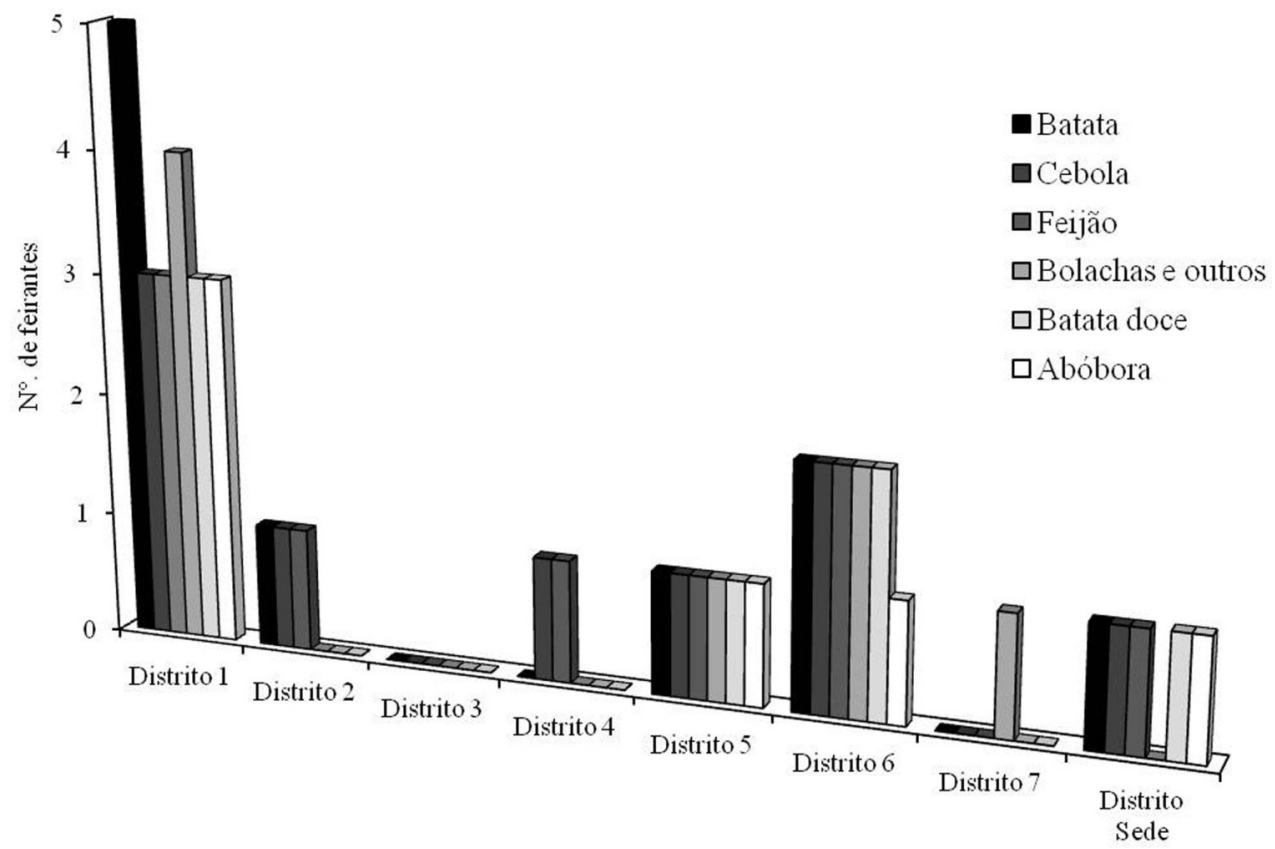

Figura 4 - Principais produtos comercializados na feira pelos feirantes de São Lourenço do Sul/RS por distrito

Fonte: Dados da pesquisa, (2015)

O tamanho total dos estabelecimentos rurais está demonstrado na Tabela 1. Percebe-se que dois (2) agricultores possuem menos de cinco hectares e os demais (12) possuem acima de cinco hectares. Dos que possuem menos de cinco hectares, aquele que produz em menos de um hectare comercializa produtos minimamente processados e produtos "medicinais", o que lhe aproxima em relação a renda obtida quando comparado aos outros agricultores com propriedades rurais maiores. Todos os agricultores se enquadram na lei da agricultura familiar, case seja considerado como critério somente o tamanho de área de seu estabelecimento rural.

A idade dos entrevistados é bem variada, apesar do número de jovens até 35 anos ser inexistente (Tabela 2). Os feirantes apresentam idades entre 35 e 75 anos. A classe quatro (59 |-66 anos) possui três (3) feirantes, correspondendo a um total de $21,43 \%$ dos quatorze (14) feirantes entrevistados.78,57\% dos entrevistados apresentam menos de 65 anos e mais de 35 anos. O fato da não identificação de pessoas com idade inferior a 35 anos entre os entrevistados pode indicar que uma parcela de jovens opta por deixar o campo e migrar para a zona urbana; possivelmente esses jovens se dedicam a outras atividades não relacionadas à produção e comercialização de produtos agrícolas. Nas possíveis atividades realizadas fora da área rural temos atividades de aprendizado em cursos profissionalizantes, realização de cursos superiores, emprego na zona urbana, entre outras atividades. Sugere-se realização de futuro estudo para maior percepção dos motivos desse presente resultado. 

Tabela 1 - Número de agricultores, por tamanho
total da área do estabelecimento

\begin{tabular}{lc}
\hline Área & $N^{\circ}$ de produtores \\
\hline$<1$ há & 1 \\
De 1 a 5 há & 1 \\
$>5$ a 10 há & 5 \\
$>10$ a 20 há & 2 \\
$>20$ há & 5 \\
Não sabe & 0 \\
\hline Total & 14 \\
\hline
\end{tabular}

Fonte: Dados da pesquisa, (2015).

Tabela 2 - Classes de idades, feirantes da Praça São Lourenço do Sul - RS

\begin{tabular}{lcccccccc}
\hline $\mathrm{i}$ & Idade & $\left(\mathrm{f}_{\mathrm{i}}\right)$ & $\left(\mathrm{f}_{\mathrm{ri}}\right)$ & $\left(\mathrm{f}_{\mathrm{p}} \%\right)$ & $\left(\mathrm{F}_{\mathrm{i}}\right)$ & $\left(\mathrm{F}_{\mathrm{ri}}\right)$ & $\left(\mathrm{P}_{\mathrm{p}} \%\right)$ & $(\mathrm{Pm})$ \\
\hline 1 & $35 \mid-43$ & 4 & 0,29 & 28,57 & 4 & 0,29 & 28,57 & 39 \\
2 & $43 \mid-51$ & 1 & 0,07 & 7,14 & 5 & 0,36 & 35,71 & 47 \\
3 & $51 \mid-59$ & 3 & 0,21 & 21,43 & 8 & 0,57 & 57,14 & 55 \\
4 & $59 \mid-66$ & 3 & 0,21 & 21,43 & 11 & 0,79 & 78,57 & 62,5 \\
5 & $66 \mid-74$ & 1 & 0,07 & 7,14 & 12 & 0,86 & 85,71 & 70 \\
6 & $74 \mid-82$ & 2 & 0,14 & 14,29 & 14 & 1,00 & 100,00 & 78 \\
\hline Total & & 14 & 1,00 & 100 & - & - & - & - \\
\hline
\end{tabular}

Fonte: Dados da pesquisa, $(2015)$; Frequência absoluta $\left(f_{i}\right)$, Frequência relativa $\left(f_{r i}\right)$, Frequência porcentual $\left(f_{p} \%\right)$, Frequência absoluta $\left(F_{i}\right)$, Frequência relativa $\left(F_{r i}\right)$, Frequência porcentual $\left(P_{p} \%\right)$, Ponto médio $(P m)$.

Em relação à escolaridade, as respostas relativas à ausência de escolaridade ou frequência até o Ensino Médio representam $72 \%$ das respostas, como revela a Figura 5. Apesar das dificuldades encontradas pelos feirantes para concluir e/ou dar continuidade aos estudos, a maior parte dos filhos dos agricultores-feirantes estudou ou está estudando; em alguns casos, o nível escolar dos filhos é superior ao dos pais. A baixa escolaridade dos feirantes deve-se possivelmente a necessidade de ajudar aos pais no trabalho, a decisão própria de não estudar e uma insuficiência ou inexistência de escolas públicas na área rural. Além disso, os relatos dos agricultores indicam que as escolas do campo ofereciam escolaridade até a $5^{a}$ série, na época que esses eram jovens. 


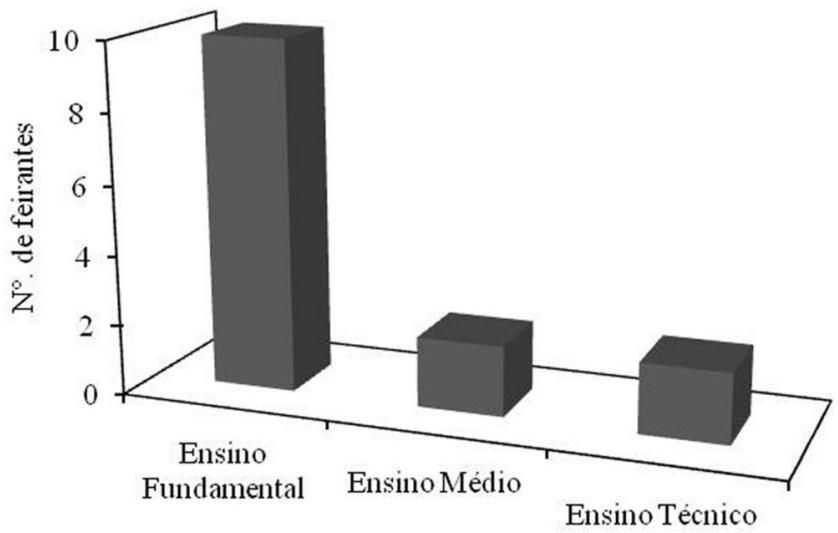

\section{Figura 5 - Níveis de escolaridade dos feirantes que atuam na Praça Central de São Lourenço do Sul - RS, 2015}

Fonte: Dados da pesquisa, (2015).

Ainda que a maioria possua um baixo nível de escolaridade, podemos dizer que os feirantes possuem e têm a capacidade de autogestão, interação e sociabilidade de conhecimentos produtivos de maneira eficiente, o que é atribuído ao conhecimento empírico adquirido ao longo dos anos, visto que muitos destes agricultores-feirantes não recebem nenhum tipo de assistência técnica.

A conformação das famílias dos feirantes tem no máximo seis integrantes, sendo formada pelo pai, mãe e seus filhos e em outros casos pelo pai com seus filhos ou a mãe com seus filhos; junto a essas famílias podem residir também outros membros (netos(as), genro, nora, sogro(a), sobrinho(a), entre outros). Quando os feirantes foram consultados sobre os integrantes da família no trabalho de produção e comercialização, as respostas foram quase unânimes em relação à participação dos familiares nas atividades da propriedade rural e da feira. Na Figura 6 observam-se somente três famílias nas quais os filhos não participam em tempo integral por estarem envolvidos com os estudos. No entanto, em seu tempo livre participam de atividades de produção e comercialização. No caso das famílias que moram com os sogros, a idade é o fator limitante para a participação nas atividades da propriedade rural e da feira.

Em outra situação verificamos que na família onde genro e filha não se dedicam a estas atividades, os mesmos trabalham em outro tipo de atividade, o que ocupa quase todo seu tempo, impedindo sua colaboração na produção e comercialização. A participação de quase todos os membros da família ameniza em alguns casos a insuficiência de mão de obra no campo. No que concerne a trabalhadores externos nas propriedades, só dois (2) dos quatorze (14) conta com ajuda externa, sendo adotado como procedimento a contratação de diarista, os demais feirantes doze (12) não possuem mão de obra externa. 


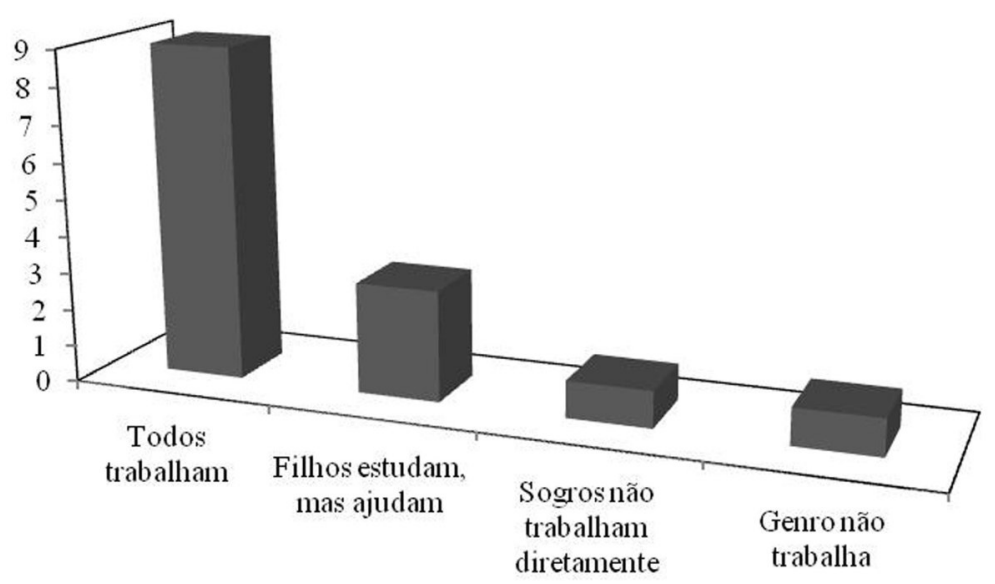

\section{Figura 6 - Participação dos integrantes da família na produção e comercialização dos produtos agrícolas, São Lourenço do Sul - RS, 2015}

Fonte: Dados da pesquisa, (2015).

Além disso, foi perguntado, "Qual é a participação da mulher na produção e comercialização dos produtos? "Constatou-se que o trabalho da mulher é bem valorizado por seus "parceiros", neste caso seus cônjuges, sendo que treze (13) dos entrevistados consideram a participação feminina fundamental para o sucesso da produção e da comercialização. No único caso em que a participação da mulher é considerada pequena, não significa que a mulher não trabalha, ao contrário, dedicase a outra atividade não relacionada à produção e comercialização, porém, em seu tempo livre, contribui com as atividades desenvolvidas pela família.

Os homens são encarregados pelo trabalho braçal e que exige maior esforço físico, sendo que as mulheres têm maior preferência pela colheita, beneficiamento e comercialização dos produtos. Pode-se perceber que a mulher cumpre um papel fundamental na agricultura familiar, sendo recorrente a dupla jornada de trabalho, visto que além de realizar as tarefas mencionadas anteriormente, também se dedica a outras atividades, como o cuidado da casa e o cuidado da educação dos filhos. Assim, podemos deduzir que a mulher é "peça chave" para o desenvolvimento, organização, luta e resistência das comunidades rurais.

O Quadro 1 mostra as dificuldades encontradas pelos produtores na produção e comercialização, assim como as vantagens de vender e comercializar na feira. Entre os entrevistados, dez (10) apontam que a principal dificuldade é a falta da mão de obra e as mudanças nas condições climáticas. Podemos indicar que a falta de mão de obra está relacionada à escassez de interessados em trabalhar no campo, assim como à falta de condições econômicas do agricultor para efetivar a contratação. Muitos jovens se distanciam do campo e vão para a cidade para realizar outras atividades não vinculadas com a agricultura, o que pode explicara inexistência de pessoas com menos de 35 anos trabalhando na feira (Tabela 2). 


\section{Quadro 1 - Principais dificuldades enfrentadas pelos agricultores- feirantes para produzir e comercializar na feira da Praça Dedê Serpa, São Lourenço do Sul - RS, 2015}

\begin{tabular}{|c|c|c|}
\hline \multirow{2}{*}{$N^{\circ}$ Feirante } & \multicolumn{2}{|c|}{ Dificuldades } \\
\hline & Produzir & Comercializar \\
\hline 1 & Falta mão de obra & Falta divulgação \\
\hline 2 & $\begin{array}{c}\text { Falta mão de obra; condições } \\
\text { climáticas }\end{array}$ & Não têm dificuldades \\
\hline 3 & Não têm dificuldades & Não têm dificuldades \\
\hline 4 & $\begin{array}{c}\text { Condições climáticas e falta de } \\
\text { estrutura }\end{array}$ & Não têm dificuldades \\
\hline 5 & Custos altos para produção & Não tem dificuldades \\
\hline 6 & Falta de assistência técnica & Não têm dificuldades \\
\hline 7 & $\begin{array}{l}\text { Custos altos para produção e } \\
\text { condições climáticas }\end{array}$ & Não têm dificuldades \\
\hline 8 & Falta de mão de obra & Não têm dificuldades \\
\hline 9 & Falta de mão de obra & $\begin{array}{l}\text { Pouca variedade de } \\
\text { produtos }\end{array}$ \\
\hline 10 & $\begin{array}{c}\text { Falta mão de obra; condições } \\
\text { climáticas }\end{array}$ & $\begin{array}{l}\text { Pouco tempo para } \\
\text { vender }\end{array}$ \\
\hline 11 & Condições climáticas & Não têm dificuldades \\
\hline 12 & $\begin{array}{c}\text { Energia elétrica muito cara para o } \\
\text { beneficiamento dos produtos }\end{array}$ & Não têm dificuldades \\
\hline 13 & Condições climáticas & Não têm dificuldades \\
\hline 14 & Falta de insumos & Não têm dificuldades \\
\hline
\end{tabular}

Fonte: Dados da pesquisa, (2015).

O clima é um fator que impõe dificuldades à produção, com períodos longos de estiagem e invernos rigorosos com temperaturas muito baixas, prejudicando de maneira direta a produção agrícola, o que gera improdutividade e eleva os custos de produção. Cabe mencionar que muitos destes agricultores-feirantes não contam com estrutura adequada para enfrentar as mudanças climáticas, como estufas, sistemas de irrigação e mecanização da lavoura.

A falta de assistência técnica no campo é outra dificuldade. Apesar da Assistência Técnica e Extensão Rural (ATER) ser a política pública mais acessada pelos agricultores, já é reconhecido que não atinge a totalidade das famílias, o que dificulta que as mesmas melhorem sua produção, sentindo-se esquecidos pela falta de políticas públicas mais eficientes, levando muitas famílias a trocar o campo pela cidade.

Outro fator relevante é a falta de insumos, a qualidade e custo da energia elétrica, o que torna o custo da produção e beneficiamento dos produtos elevados. Entre a falta de insumos podemos mencionar adubos orgânicos, fertilizantes orgânicos, sementes, equipamentos agrícolas entre outros. Alguns dos feirantes entendem como principal insumo a utilização de energia elétrica para agregar valor a seus produtos, o que aumenta a comercialização na feira e, consequentemente, a renda. No entanto, muitas vezes a energia elétrica que chega às áreas rurais é deficiente, pois ocorrem interrupções no fornecimento dessa, o que dificulta o processo produtivo.

No que diz respeito às dificuldades encontradas, onze (11) feirantes asseguraram não ter dificuldade alguma na etapa de comercialização. Cabe mencionar que 
eles utilizam parte do espaço da praça central do município, a qual é cedida pela prefeitura para a comercialização dos produtos oriundos da agricultura familiar. Um entrevistado mencionou a falta divulgação da feira. No entanto, os relatos dos feirantes e de representantes do poder público indicam que a feira tem aproximadamente 40 anos de fundação, atuando sempre no mesmo lugar, na praça central. O que nos leva a pensar que possivelmente não se trate de divulgação e sim falta de conscientização dos consumidores quanto ao consumo dos produtos locais, de estação e inclusive produtos livres de agrotóxicos oriundos da agricultura familiar, todos eles à disposição do consumidor. Outra dificuldade encontrada é a falta de variedade de produtos para comercialização, atribuindo-se a isso às mudanças climáticas, à falta de mão de obra, à falta de assistência técnica e à falta de estrutura para produção. Fazem referência à necessidade de maior presença dos governos estadual e federal, o que, segundo os feirantes, permitiria políticas mais específicas e mais eficientes para a agricultura familiar.

Para o escoamento da produção a totalidade de feirantes utiliza como principal canal de comercialização a feira (Quadro 2). Dentre esses, nove (9) feirantes utilizam somente a feira para comercializar seus produtos. De acordo com os feirantes, a vantagem principal de comercializar na feira é a eliminação do atravessador, tendo desta maneira uma maior rentabilidade. Outras vantagens citadas foram: clientes fixos, preço justo, pagamento à vista e possibilidade de interagir com os consumidores. Como desvantagens têm-se: falta de infraestrutura do local, falta de organização e falta de divulgação da feira. Pode-se afirmar que a feira é um canal para obter um desenvolvimento socioeconômico tanto para os produtores como para a região. As desvantagens apresentadas pelos feirantes indicam a necessidade de ações para melhorar as formas de organização social e política dos mesmos e consequentemente a solução dos problemas apresentados.

\section{Quadro 2 - Canais de comercialização utilizados, pelos agricultores- feirantes, São Lourenço do Sul - RS, 2015}

\begin{tabular}{|c|c|c|c|}
\hline Somente em férias & Propriedade & Porta em porta & PAA \\
\hline$X$ & $X$ & $X$ & \\
\hline$X$ & & & \\
\hline$X$ & & & \\
\hline$X$ & $X$ & & \\
\hline$X$ & & & \\
\hline$X$ & & & \\
\hline$X$ & & & \\
\hline$X$ & $X$ & & \\
\hline$X$ & & & \\
\hline$X$ & & & \\
\hline$X$ & & & \\
\hline$X$ & & & \\
\hline$X$ & & & \\
\hline$X$ & & & \\
\hline Total & & & \\
\hline
\end{tabular}

Fonte: Dados da pesquisa, (2015). 
Cinco (5) feirantes utilizam outros canais de comercialização ou a combinação de diferentes canais. Cinco (5) feirantes relataram que vendem seus produtos na propriedade, um (1) realiza vendas de porta em porta e um (1) comercializa no Programa de Aquisição de Alimentos - PAA (Quadro 2). O PAA é uma política pública que viabiliza compras institucionais da agricultura familiar. A aquisição dos alimentos pode ser feita por escolas, universidades, creches, hospitais públicos, quartéis entre outros (Pierri, 2010). A não utilização desse canal pelos agricultores pode estar relacionada com a redução de recursos e contratos do programa, a falta de informação, a vontade própria de não comercializar nesses mercados, a falta de organização e a insuficiência de produtos.

A renda média dos feirantes pode variar de acordo com a quantidade e variedade de produtos oferecidos; outro fator importante que influi é a sazonalidade. A renda média bruta dos feirantes é de $\mathrm{R} \$ 1.363,85$ mensais. No Quadro 3 pode-se observar as respostas dadas às perguntas: Qual é o nível de satisfação com a renda proveniente da comercialização dos produtos? Satisfeito ou insatisfeito. Por quê? De fato, treze (13) dos entrevistados afirmaram que a comercialização na feira "dá para pagar as dívidas" e fornecer "bons lucros", ficando evidente a importância das feiras livres quanto a geração de renda das famílias e para o desenvolvimento da região.

\section{Quadro 3 - Satisfação dos feirantes da Praça Dedê Serpa do São Lourenço do Sul em relação a renda obtida e o motivo da satisfação e/ou insatisfação}

\begin{tabular}{|c|c|c|}
\hline Satisfeito & Insatisfeito & Por quê? \\
\hline$x$ & & "dá para pagar os gastos da família" \\
\hline$x$ & & "Renda muito boa" \\
\hline $\mathrm{x}$ & & "paga gastos da família" \\
\hline$x$ & & "pode viver bem" \\
\hline$x$ & & "paga as dividas" \\
\hline \multirow[t]{2}{*}{$x$} & & "pode viver bem" \\
\hline & $x$ & "não da para pagar as contas" \\
\hline$x$ & & "curte do trabalho" \\
\hline$x$ & & "paga as dividas" \\
\hline$x$ & & "paga as dividas" \\
\hline$x$ & & "paga gastos da família" \\
\hline$x$ & & "Bons lucros" \\
\hline$x$ & & "paga as dívidas" \\
\hline$x$ & & "da para trocar o carro" \\
\hline Total & & 14 feirantes \\
\hline
\end{tabular}

Fonte: Dados da pesquisa, (2015). 
Quando perguntados sobre sua produção (convencional ou orgânica), 50\% dos entrevistados considera sua produção como orgânica; $36 \%$ confirmam que sua produção é convencional, alegando que nesse modelo a produtividade é maior;14\% consideram sua produção convencional pelo fato de seus vizinhos usarem fertilizantes e adubos químicos, o que não permitiria o cultivo de produtos orgânicos. Essa porcentagem elevada de produção convencional se configura como uma oportunidade para a aplicação de ferramentas e métodos de conversão a uma produção orgânica.

\section{CONCLUSÃO}

A feira de produtos agrícolas que ocorre na praça central de São Lourenço do Sul - RS é formada por pequenos grupos de agricultores pertencentes à agricultura familiar, sendo estes uma pequena parte do sistema agroalimentar dominante, voltados para a sobrevivência e o consumo popular.

A ausência de atravessador, a interação entre feirante e consumidor e a obtenção de renda satisfatória são pontos positivos da feira da agricultura familiar de São Lourenço do Sul. Apesar disso, melhorias de infraestrutura devem ser realizadas para fortalecer esse meio de comercialização. Existe possibilidade de fortalecimento da produção orgânica no município.

Os resultados obtidos nesta pesquisa chamam a atenção para a necessidade de melhoria da produção e comercialização dos produtos da agricultura familiar de base orgânica, por exemplo, promovendo espaços de conscientização dos consumidores, capacitando os agricultores para uma melhor gestão de sua propriedade, desenvolvendo estratégias para aumentar a participação dos agricultores dos distritos com menor participação na feira, oportunizando outros espaços de feira em outros bairros da cidade e outras estratégias que garantam a geração de renda e permanência do homem no campo, assim como o desenvolvimento local.

Apesar das dificuldades encontradas pelos agricultores para produzir e comercializar seus produtos agrícolas, esses encontram nas feiras livres a forma de garantir a renda e a sobrevivência de sua família. Fica evidente a importância das feiras livres para garantir a segurança e autonomia alimentar, assim como o desenvolvimento rural, fazendo-se necessário o ajuste de políticas públicas específicas, voltadas aos pequenos agricultores-feirantes com respeito as diferentes culturas e condições geográficas de cada região.

\section{REFERÊNCIAS}

BACCARIN, J. G. et al. Conformidade na distribuição dos créditos do PRONAF: análise em relação ao número e à renda bruta de estabelecimentos da agricultura familiar nas regiões geográficas brasileiras. Geografia. Rio Claro. v. 41, n. 3, p. 403-566. Set/dez. 2016.

INSTITUTO BRASILEIRO DE GEOGRAFIA E ESTATÍSTICA. IBGE. Censo Demográfico. 2010. Disponível em <http://www.sidra.ibge.gov.br/>. Acesso em 05 de dezembro de 2014. 
MEDEIROS, M; MARQUES, F. C. Plantando ideias inovadoras, colhendo transformações na agricultura familiar: a produção de base ecológica e a construção social de mercados no sul do Rio Grande do Sul. In: CONTERATO, M. A.... [et al.] (Org.). Mercados e agricultura familiar: interfaces, conexões e conflitos. Porto Alegre: Ed. Via Sapiens, 2013. p. $114-132$.

Ministério de desenVolvimento AgrÁRIO. MDA. Plano Safra da Agricultura Familiar 2012/2013. Disponível em <http://portal.mda.gov.br/plano-safra/arquivos/ view/Cartilha_Plano_Safra.pdf. Acesso em 05 de dezembro de 2014.

PANZUTTI, N; MONTEIRO, A.V. Agricultura familiar e políticas públicas. Cadernos Ceru v. 25, n. 2, 06. Disponível em:https://www.revistas.usp.br/ceru/article/viewFile/ 98767/97344. Acesso em: 15 mar. 2018.

PIERRI, M.C.Q.M. Um Recorte em Território Artificializado: Agricultura Familiar na Feira dos Goianos-Gama/DF.206 páginas Dissertação. (Mestrado em Agronegócios) - Universidade de Brasília, Brasília, 2010.

REDE RURAL. CCA - Circuito curto agroalimentar. Disponível em: <http:// www.rederural.pt/index.php/pt/2013-10-30-12-05-36/o-que-e-um-cca/conceito-decircuito-curto-agroalimentar-cca>. Acesso em: 15 mar. 2018.

SANTOS, M. Da Totalidade ao Lugar. São Paulo: Editora da Universidade de São Paulo, 2005.

SINGER, P. Introdução à Economia Solidária. São Paulo: Fundação Perceu Abramo, 2002.

STEINER, P. A Sociologia Econômica. São Paulo: Editora Atlas S.A., 2006.

Recebido em janeiro de 2017

Revisado em abril de 2018

Aceito em julho de 2018 